\title{
Quantitative Analysis Methodology of Non-deterministic Causal Relationship in Risk Analysis
}

\author{
Dewang Ren and Wei Zheng \\ National Engineering Research Center of Rail Transportation Operation and \\ Control System, Beijing Jiaotong University, Beijing 100044, China
}

\begin{abstract}
In the safety-critical systems, potential hazard may jeopardize the safety of system, which can even lead to catastrophic accident. The occurrence of accident contains deterministic and non-deterministic causal logic relationships. The former refers to technical aspects, where event tree and fault tree could be applied to analyze. The latter mainly refers to operational aspects. Due to uncertainties and lack of data, Bayesian network becomes the appropriate tool. However, how to determine the conditional probability table is a difficult task. In this paper, a new conditional probability allocation method based on fuzzy logic is proposed to reference posterior probability. Before quantitative analysis, the risk model of influencing factors may be established. Finally, the proposed method is applied to evaluate human error probability.
\end{abstract}

Keywords: Bayesian network, non-deterministic causal logic relationship, fuzzy logic, evidence theory

\section{Introduction}

In the safety-critical system, causes of accident include "hard" and "soft" factors. Because the "hard" factors are associated with design and structure of system, and failure mode and mechanism are explicit, the causal relationships leading to accident are deterministic, which belongs to technical aspects. However, the "soft" factors refer to operational aspects. They are not relevant to the structure of system, but because of its complexity and uncertainty as well as lack or loss of data, those causal relationships are uncertain.

For the "hard" factors, event tree and fault tree has been used for risk analysis, they are combined to establish the "bow-tie" model. In the subway and industry, the practical application has shown that the model has a good effect. It not only can identify the causes of accident, but also evaluate the risk acceptable level [1-2]. The causes of accident mostly contain equipment failure and errors of human and organization. In order to take those causes into consideration, the analysis framework based on hybrid causal logic has been presented [3]. Combined with event sequence, fault tree and Bayesian network, the hybrid causal methodology is applied to construct causal failure model in the aviation [4]. In paper [5], this method is used for probability risk assessment and management of the socio-technical system for the sake of risk identification, risk indicator assessment, safety management and causes of accident analysis. Sklet utilizes the hybrid methodology to analyze risk influencing factors such as technical factors, operational factors, human and organizational factors, which is combined with barrier block diagram, fault tree, event tree and influence diagram [6]. In the probability safety assessment (PSA), Mosleh builds the influent model for the structural and behavioral aspects of organization factors, where $\omega$ method is used to analyze interactive influence among organizational factors [7]. In the nuclear domain, Bayesian network and $\omega$ method are combined to research the influence of organizational factors in PSA [8]. 
In addition, Bayesian network is ideal technique for prediction and diagnosis. For instance, in the offshore drilling industry, the work flow chart is converted to Bayesian network to analyze the impact of five factors: the hydraulic factor, mechanical factor, human, software and hardware [9]. In the paper [10], event tree and fault tree are united to set up "bow tie" model, which is converted to Bayesian network for probability updating and sequence learning. After description of risk problems, determination of risk influencing factors and identification of failure modes, Bayesian network is constructed to quantitatively analyze causal relationships and interactive processes between variables [11].

In this paper, the quantitative analysis method of non-deterministic causal relationships in risk analysis based on Bayesian network is proposed, which includes both modeling of influent diagram and quantitative analysis. The rest of the paper is organized as follows. Section 2 describes the proposed methodology. How to build the model is given in Section 3. Section 4 is devoted to explanation of the quantitative analysis approach. This approach is applied to evaluate the human error probability of driver of the high-speed railway system in Section 5 while the conclusion is presented in Section 6.

\section{Overview of the Proposed Methodology}

The influences of uncertain factors can be divided into two types: direct and indirect interactions. In order to take those interactions into consideration to model and analyze the non-deterministic causal relationships, this proposed methodology contains both modeling stage and analyzing stage. This section gives an overview of the proposed methodology to introduce the major steps shown in the Figure 1. At the modeling stage, firstly, the critical event (top event) and its influencing factors is identified, then the causal relationships among them should be determined to build influence diagram, at last, it can be transformed to Bayesian network. At the analyzing stage, first of all, the node weight is given with the node score, secondly, through the weights can the network parameters be determined including prior probabilities of parent nodes and conditional probabilities of intermediate nodes, lastly, the posterior probabilities will be evaluated by Bayes' theorem using the GeNIe software.

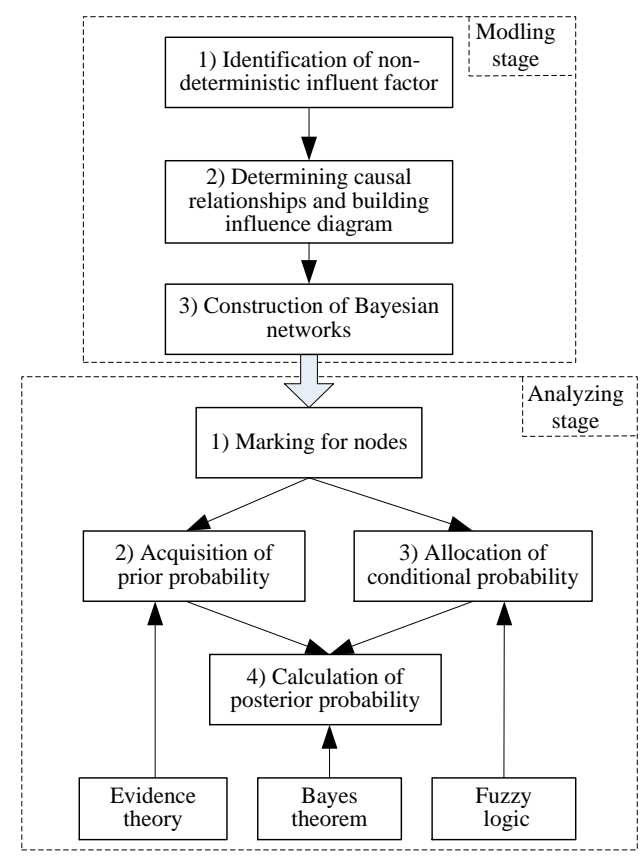

Figure 1. Major Steps of the Proposed Methodology 


\section{Approach of Modeling Influence Diagram}

All the interactive relationships between influencing factors and equipment or among influencing factors are uncertain. It mostly refers to two aspects: one is the uncertain structure because of their complicated relationships, the other is varying values of influencing factors with different situations.

Almost of the influencing factors are soft factors. The interaction between soft factors and equipment includes operation and maintenance, which are effected by subjective factors such as knowledge, pressure and emotion. Therefore, the failure probabilities of equipment by different "soft" factors are various with different contributions.

Before implementing quantitative analysis, the causal relationships among influencing factors must be determined, namely constructing influence diagram. Firstly, for purpose of generation of influence diagram, an output table and input table would be created to store the critical event and influencing factors respectively, similarly an intermediate table should be created which is empty. The generation process of influence diagram is shown as Figure 2. The direct influencing factors for critical events can be determined as well as the indirect ones through this process.

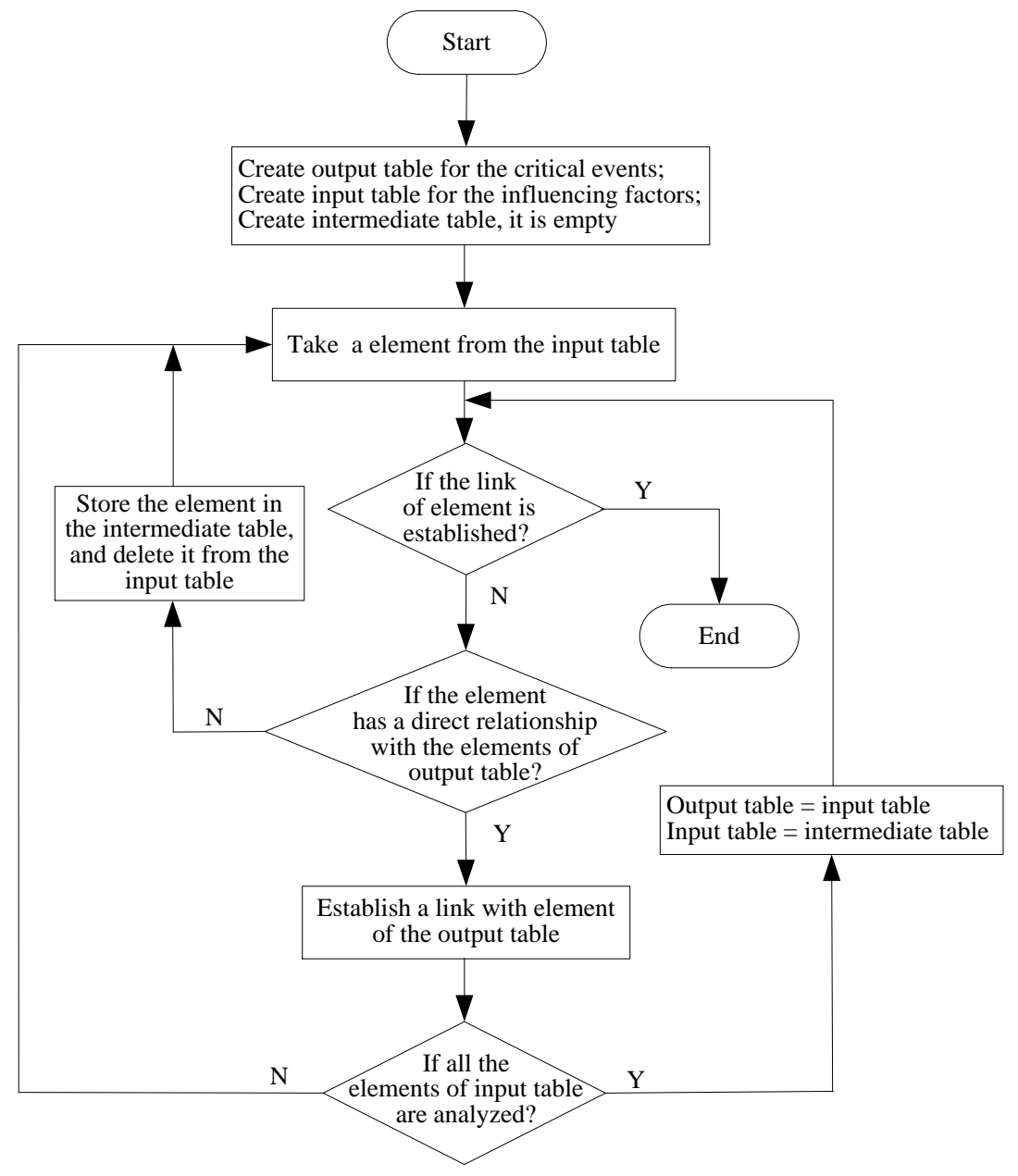

Figure 2. Flow Chart for Generation of Influence Diagram

As the modeling process in Figure 2, the causal relationships between critical events and influencing factors can be built, namely influence diagram, which is hierarchical shown in Figure 3. After establishing influence diagram, there is a need for quantitative analysis that it may be converted to Bayesian network. 


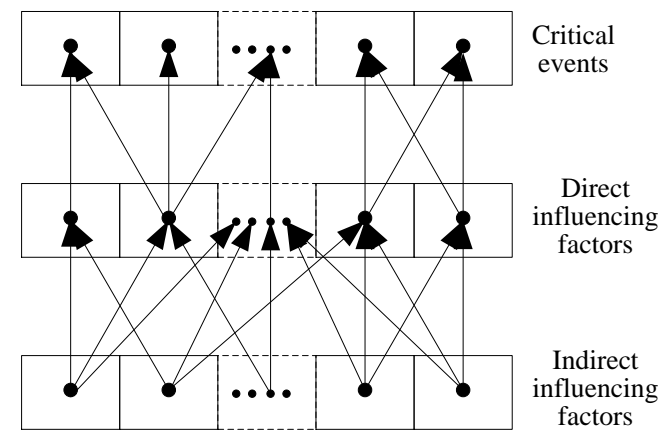

Figure 3. Influence Diagram between Critical Events and Influencing Factors

\section{Method of Quantitative Analysis}

In order to explain the quantitative analysis method, the Bayesian network in Figure 4 is taken as an example. Node A and B are the parent nodes, node C is child node. They have three states: desirable, medium and undesirable states. Presuming that the states of node A are high, medium and low, node B with three states of much, medium and little, and node $\mathrm{C}$ with good, medium and bad, the quantitative analysis method can be illustrated step by step.

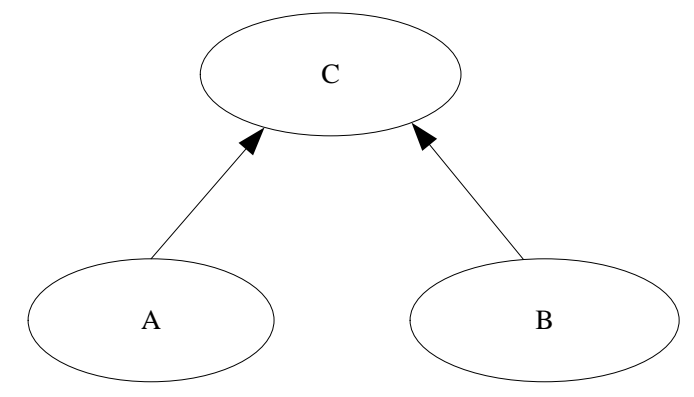

Figure 4. Simple Bayesian Network

\subsection{Marking for Nodes}

For a given scenario, the weight of node may be different for different actions, which refers to the relative importance of each node. Generally, the method based on expert judgment is used to determine the weights of node. The weight can be evaluated through values ranging from 0 to 100 with the increment of 10 for the level, of which 0 stands for the worst conditions and 100 for the best [12].

Once the weights of parent nodes are given, the prior probabilities can be obtained, and the conditional probabilities can be assigned. Therefore, the goal of quantitative analysis can be achieved.

\subsection{Acquisition of Prior Probability of Parent Node}

Due to actual and certain data, expert judgment is required. Expert judgment suffers from subjectivity and variability, the reliability of data will decrease. Multi expert knowledge is combined using Dempster-Shafer evidence theory to solve that problem [13-14]. In Figure 4, for each node three different states can be assigned. The degree of belief of each state is assigned by experts, which is denoted by $b\left(p_{i}\right)$ and can be characterized by the following equations:

$$
b\left(p_{i}\right) \rightarrow[0,1] ; \quad b(\varphi)=\left(; \quad \sum_{p_{i} \subseteq P} b\left(p_{i}\right)=1\right.
$$


By the DST combination rule, multiple evidences can be combined. If there are $n$ different knowledge sources, the sum combination is depicted as follows:

$$
b_{1-n}=b_{1} \oplus b_{2} \oplus \cdots \oplus b_{n}
$$

Assuming that knowledge sources are independent, this combination rule uses a normalizing factor $(1-k)$ to develop an agreement among the multiple knowledge sources. If the $b_{1}\left(p_{a}\right)$ and $b_{2}\left(p_{b}\right)$ are two sets of evidence for the same node, the combination rule uses the relation in equation (3) to combine the evidences:

$$
\left[b_{1} \oplus b_{2}\right]\left(p_{i}\right)=\left\{\begin{array}{cc}
0 & p_{i}=\varphi \\
\frac{\sum_{p_{a} \cap p_{b}=p_{i}} b_{1}\left(p_{a}\right) b_{2}\left(p_{b}\right)}{1-k} & p_{i} \neq \varphi
\end{array}\right.
$$

In the above equation, it denotes the combined knowledge of two experts for a node, and $k$ measures the degree of conflict between the two experts, which is determined by the factor:

$$
k=\sum_{p_{a} \cap p_{b}=\phi} b_{1}\left(p_{a}\right) b_{2}\left(p_{b}\right)
$$

Taking node A in Fig.4 as an example, the combination process can be explained in the Tab.1. $\{0.8,0.1,0.1\}$ is assigned to the node A by expert 1 , and $\{0.85,0.1,0.05\}$ by expert 2 . Though the combination, the reliable prior probability of node $\mathrm{A}$ is $\{0.97,0.01,0.01\}$.

Table 1. Evidence Combination for the Node A

\begin{tabular}{lllll}
\hline & Expert 2 & $\{$ High $\}$ & $\{$ Medium $\}$ & $\{$ Low $\}$ \\
\hline Expert 1 & & 0.85 & 0.1 & 0.05 \\
$\{$ High $\}$ & 0.8 & $\{$ High $\}=0.68$ & $\{$ High $\}=0.08$ & $\{\varphi\}=0.04$ \\
$\{$ Mediu & 0.1 & $\{$ High $\}=0.085$ & $\{$ Medium $\}=0.01$ & $\{$ Low $\}=0.005$ \\
m $\}$ & & $\{\varphi\}=0.085$ & $\{$ Low $\}=0.01$ & $\{$ Low $\}=0.005$ \\
$\{$ Low $\}$ & 0.1 & $0.085+0.04=0.125$ & & \\
& $k$ & $0.68+0.085+0.08=0.845$ & 0.01 & $0.005+0.01+0.005=0.02$ \\
& & $0.845 / 0.875=0.97$ & $0.01 / 0.875=0.01$ & $0.02 / 0.875=0.02$ \\
\hline
\end{tabular}

\subsection{Allocation of Conditional Probability for Intermediate Node}

In general, the allocation of conditional probability suffers from subjectivity and uncertainty. Another disadvantage is that the number of state combination increases exponentially as the node number grows. In order to solve those problems and make it convenient for allocation, fuzzy logic is used to achieve automatic allocation.

(1) Transformation of Input Data

In Figure 4, the input data is the node scores, which is discrete. They can be quantized uniformly into 11 levels, the corresponding relationships is shown in Table 2.

Table 2. Uniform Quantization of Input and Output Values

\begin{tabular}{cccccccccccc}
\hline $\begin{array}{c}\text { Quantization } \\
\text { level }\end{array}$ & 0 & 1 & 2 & 3 & 4 & 5 & 6 & 7 & 8 & 9 & 10 \\
\hline Actual & 0 & 10 & 20 & 30 & 40 & 50 & 60 & 70 & 80 & 90 & 100 \\
\hline
\end{tabular}




\section{value}

(2) Division of Fuzzy Space of Input and Output Data

The linguistic of premises of fuzzy rules consist of the fuzzy input space, and the fuzzy output space is composed by the linguistic of consequences of fuzzy rules. The value of each linguistic variable is a set of fuzzy language name, which constitutes a language name set. Each language name is fuzzy set with similar domain of discourse. The division of fuzzy space is applied to determine the number of fuzzy linguistic name of linguistic variable.

In Figure 4, the domain of discourse for the input and output data is $[0,100]$. The division of fuzzy space is completed according to the states of node. Namely, node A has three fuzzy levels: high, medium and low, similarly, node B: much, medium and little, node C: good, medium and bad. Membership function of input and output data select the triangle function, its width is 50 (half of the bottom edge of triangle). The curve of membership function is shown in Figure 5. The list of membership function is descripted in Table 4.

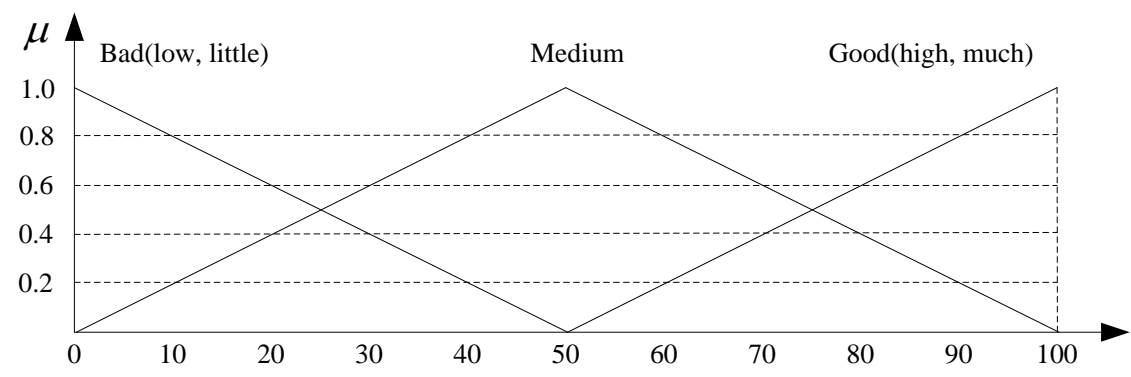

Figure 5. Membership Function Curve of Input and Output Values

Table 4. Membership Functions of Language Variables

\begin{tabular}{cccccccccccc}
\hline$\mu \quad$ Domain & 0 & 10 & 20 & 30 & 40 & 50 & 60 & 70 & 80 & 90 & 100 \\
Fuzzy variable & & & & & & & & & & \\
\hline Bad(low, little) & 1 & 0.8 & 0.6 & 0.4 & 0.2 & 0 & 0 & 0 & 0 & 0 & 0 \\
Medium & 0 & 0.2 & 0.4 & 0.6 & 0.8 & 1 & 0.8 & 0.6 & 0.4 & 0.2 & 0 \\
Good(high, much) & 0 & 0 & 0 & 0 & 0 & 0 & 0.2 & 0.4 & 0.6 & 0.8 & 1 \\
\hline
\end{tabular}

\section{(3) Generation of Fuzzy Rule}

Under the condition of a state combination of parent nodes, the corresponding and appropriate state of child node can be determined solely. Therefore, the conditional probability can be assigned. For the Bayesian network in Figure 4, the state allocation of child node is identified in Table 4.

Table 4. State Allocation Rules

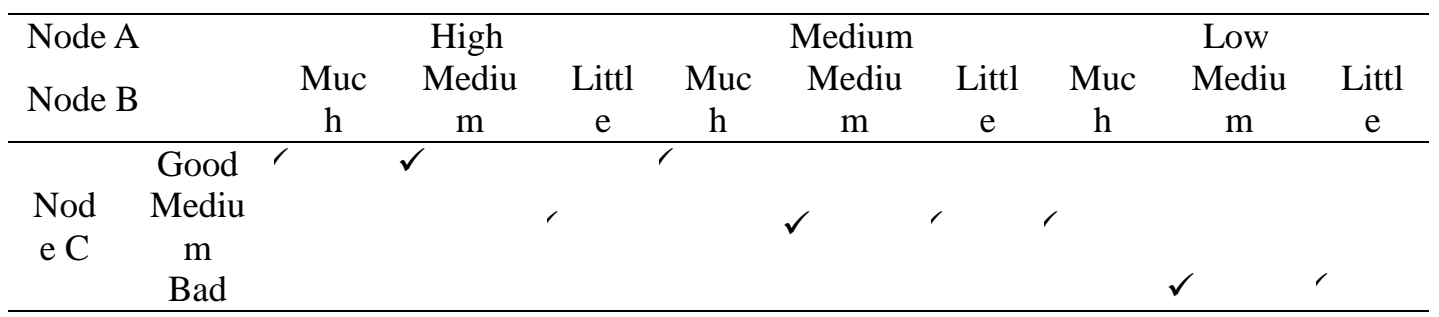


In this way, one state combination of parent nodes and its corresponding state of child node forms one fuzzy rule, where its premise is the parent nodes' state combination, and its consequence is the child node's state. There are 9 fuzzy inference rules in the Bayesian network of Figure 4.

$R_{1}$ : If $\mathrm{A}$ is high, and $\mathrm{B}$ is much, then $\mathrm{C}$ is good.

$R_{2}$ : If $\mathrm{A}$ is high, and $\mathrm{B}$ is medium, then $\mathrm{C}$ is good.

$R_{3}$ : If $\mathrm{A}$ is high, and $\mathrm{B}$ is little, then $\mathrm{C}$ is medium.

$R_{4}$ : If $\mathrm{A}$ is medium, and $\mathrm{B}$ is much, then $\mathrm{C}$ is good.

$R_{5}:$ If $\mathrm{A}$ is medium, and $\mathrm{B}$ is medium, then $\mathrm{C}$ is medium.

$R_{6}$ : If $\mathrm{A}$ is medium, and $\mathrm{B}$ is little, then $\mathrm{C}$ is medium.

$R_{7}$ : If $\mathrm{A}$ is low, and $\mathrm{B}$ is much, then $\mathrm{C}$ is medium.

$R_{8}$ : If $\mathrm{A}$ is low, and $\mathrm{B}$ is medium, then $\mathrm{C}$ is bad.

$R_{9}$ : If $\mathrm{A}$ is low, and B is little, then $\mathrm{C}$ is bad.

(4) Allocation of conditional probability

Assuming that the score of node A is 80 and node B' score is 90 . Through fuzzily processing, they linguistic variables are as follows:

Node A, 80: \{0.6、0.4、0\}. The blue line in Fig.5 emphasizes it.

Node B, 90: $\{0.8 、 0.2 、 0\}$. It is denoted by the red line in Fig.5.

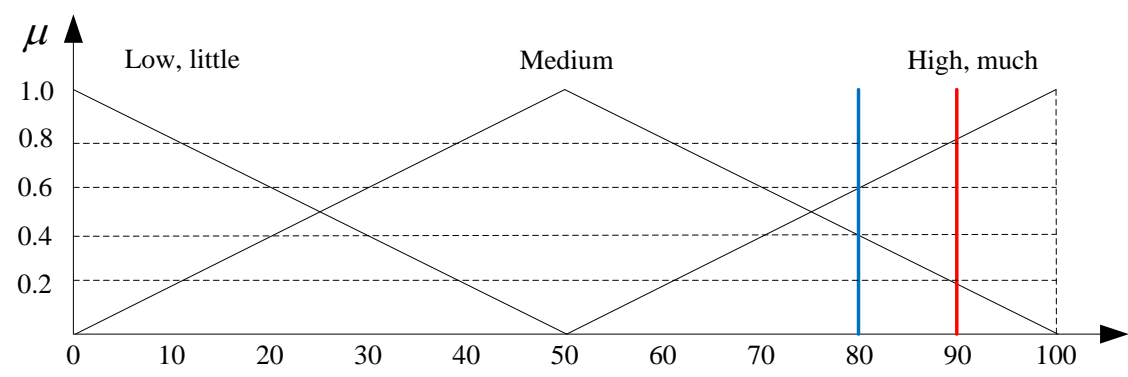

Figure 6. Language Variables Fuzzification of Node A and B

After fuzzily processing of node $\mathrm{A}$ and $\mathrm{B}$, the rule $R_{1} \sim R_{9}$ are activated to inference the linguistic variable of node $\mathrm{C}$. The confidence of each rule can be determined using maximizing operation shown as follows:

$$
\begin{aligned}
& R_{1}: \omega_{1}=\max \{0.6,0.8\}=0.8 \\
& R_{2}: \omega_{2}=\max \{0.6,0.2\}=0.6 \\
& R_{3}: \omega_{3}=\max \{0.6,0\}=0.6 \\
& R_{4}: \omega_{4}=\max \{0.4,0.8\}=0.8 \\
& R_{5}: \omega_{5}=\max \{0.4,0.2\}=0.4 \\
& R_{6}: \omega_{6}=\max \{0.4,0\}=0.4 \\
& R_{7}: \omega_{7}=\max \{0,0.8\}=0.8 \\
& R_{8}: \quad \omega_{8}=\max \{0,0.2\}=0.2 \\
& R_{9}: \quad \omega_{9}=\max \{0,0\}=0
\end{aligned}
$$


In order to make the allocation of conditional probability independent of the prior knowledge, the following operations need to be defined.

Operation 1: $P_{c o n G}=\left(O-V_{G 1}\right) / W_{G}, P_{c o n B}=P_{c o n M}=\left(1-P_{c o n G}\right) / 2$

Operation 1': $P_{\text {conG }}=\left(V_{G 2}-O\right) / W_{G}, P_{c o n B}=P_{c o n M}=\left(1-P_{\text {conG }}\right) / 2$

Operation 2

$P_{c o n B}=\left(V_{B 2}-O_{1}\right) / W_{M}, P_{c o n G}=\left(O_{2}-V_{B 2}\right) / W_{M}, P_{c o n M}=1-P_{c o n B}-P_{c o n M}$

Operation 2'

$P_{\text {conB }}=\left(O_{1}-V_{B 1}\right) / W_{M}, P_{\text {conG }}=\left(V_{G 2}-O_{2}\right) / W_{M}, P_{\text {conM }}=1-P_{\text {conB }}-P_{\text {conM }}$

Operation 3: $P_{\text {conB }}=\left(O-V_{B 1}\right) / W_{B}, P_{c o n G}=P_{\text {conM }}=\left(1-P_{\text {conB }}\right) / 2$

Operation 3': $P_{\text {conB }}=\left(V_{B 2}-O\right) / W_{B}, P_{\text {conG }}=P_{\text {conM }}=\left(1-P_{\text {conB }}\right) / 2$ where, $P_{c o n G}, P_{c o n B}$ and $P_{c o n M}$ are the conditional probability of the desirable, undesirable and medium and states respectively. $O$ is the output of fuzzy inference. $W_{G}$, $W_{B}$ and $W_{B}$ are the interval widths of membership function of the desirable, undesirable and medium and states respectively. $V_{G 1}$ and $V_{G 2}$ are the endpoint values of interval for the desirable state, similarly, $V_{B 1}$ and $V_{B 2}$ for the desirable state.

The allocating process of conditional probability is descripted in Fig.7, which is not sensitive to the change of input data and relatively stable.

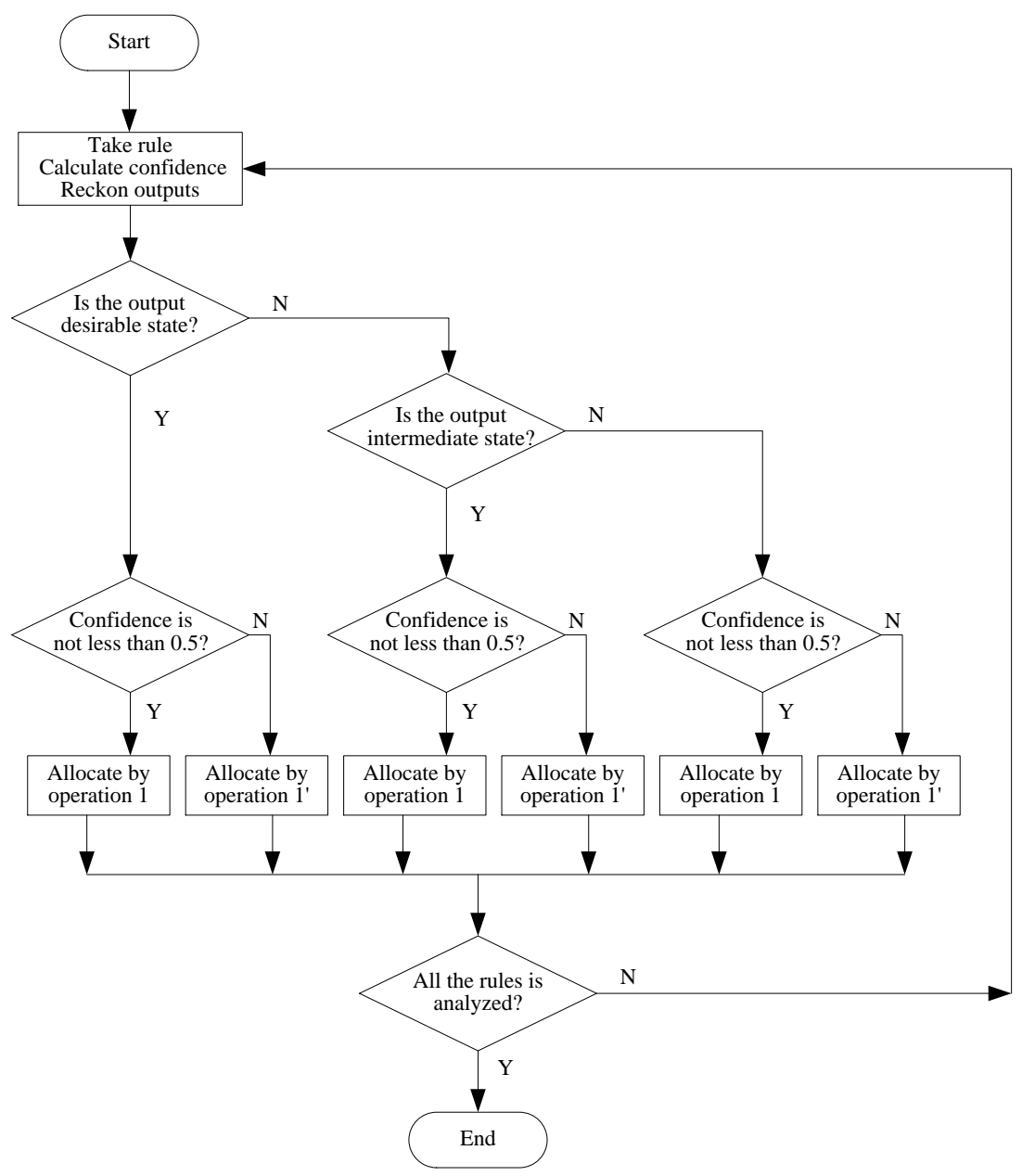

Figure 7. Flow Chart of Conditional Probability Allocation 
Taking Bayesian network in Figure 4 as an example, the allocation process can be illustrated. From the Fig.8, it can be seen that the output of inference rules are 80, $(30,70)$, $(40,60),(20,80),(20,80),(40,60), 40,50$.

(1) If the output state of inference rule is desirable (Good), for example, $R_{1}$,

$\mathrm{P}(\mathrm{C}=$ Good $\mid \mathrm{A}=$ High, $\mathrm{B}=$ Much $)=(90-50) / 50=0.8$

$\mathrm{P}(\mathrm{C}=$ Medium $\mid \mathrm{A}=$ High, $\mathrm{B}=$ Much $)=(1-0.8) / 2=0.1$

$\mathrm{P}(\mathrm{C}=\mathrm{Bad} \mid \mathrm{A}=\mathrm{High}, \mathrm{B}=\mathrm{Much})=(1-0.8) / 2=0.1$

(2) If the output state of inference rule is medium (Medium), for example, $R_{3}$, $\mathrm{P}(\mathrm{C}=\mathrm{Good} \mid \mathrm{A}=$ High, $\mathrm{B}=$ Little $)=(70-50) / 100=0.2$

$\mathrm{P}(\mathrm{C}=\mathrm{Bad} \mid \mathrm{A}=$ High, $\mathrm{B}=$ Little $)=(50-30) / 100=0.2$

$\mathrm{P}(\mathrm{C}=$ Medium $\mid \mathrm{A}=$ High, $\mathrm{B}=$ Little $)=1-0.2-0.2=0.6$

(3) If the output state of inference rule is undesirable (Bad), for example, $R_{8}$,

$\mathrm{P}(\mathrm{C}=\mathrm{Bad} \mid \mathrm{A}=$ Low, $\mathrm{B}=$ Medium $)=(40-0) / 50=0.8$

$\mathrm{P}(\mathrm{C}=$ Good $\mid \mathrm{A}=$ Low, $\mathrm{B}=$ Medium $)=(1-0.8) / 2=0.1$

$\mathrm{P}(\mathrm{C}=$ Medium $\mid \mathrm{A}=$ Low, $\mathrm{B}=$ Medium $)=(1-0.8) / 2=0.1$

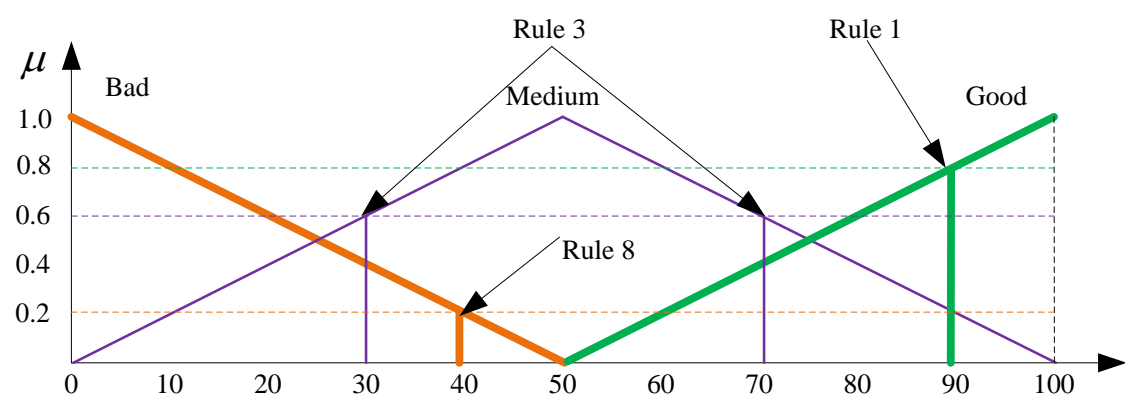

Figure 8. Fuzzy Inference Output of Rule 1,3,7

Through the allocation algorithm based on fuzzy logic, the conditional probabilities of intermediate nodes are assigned shown in Table 6.

Table 6. Conditional Probabilities Generated from Fuzzy Rules

\begin{tabular}{|c|c|c|c|c|c|c|c|c|c|c|}
\hline \multirow{2}{*}{\multicolumn{2}{|c|}{$\begin{array}{l}\text { Node A } \\
\text { Node B }\end{array}$}} & \multicolumn{3}{|c|}{ High } & \multicolumn{3}{|c|}{ Medium } & \multicolumn{3}{|c|}{ Low } \\
\hline & & $\begin{array}{c}\text { Muc } \\
\mathrm{h}\end{array}$ & $\begin{array}{c}\text { Mediu } \\
\mathrm{m}\end{array}$ & $\begin{array}{c}\text { Littl } \\
\mathrm{e}\end{array}$ & $\begin{array}{c}\text { Muc } \\
\mathrm{h}\end{array}$ & $\begin{array}{c}\text { Mediu } \\
\mathrm{m}\end{array}$ & $\begin{array}{c}\text { Littl } \\
\mathrm{e}\end{array}$ & $\begin{array}{c}\text { Muc } \\
\mathrm{h}\end{array}$ & $\begin{array}{c}\text { Mediu } \\
\mathrm{m}\end{array}$ & $\begin{array}{c}\text { Littl } \\
\mathrm{e}\end{array}$ \\
\hline \multirow{3}{*}{$\begin{array}{l}\text { Nod } \\
\text { e C }\end{array}$} & Good & 0.8 & 0.6 & 0.2 & 0.1 & 0.3 & 0.3 & 0.1 & 0.1 & 0 \\
\hline & $\begin{array}{c}\text { Mediu } \\
\text { m }\end{array}$ & 0.1 & 0.2 & 0.6 & 0.8 & 0.4 & 0.4 & 0.8 & 0.1 & 0 \\
\hline & $\mathrm{Bad}$ & 0.1 & 0.2 & 0.2 & 0.1 & 0.3 & 0.3 & 0.1 & 0.8 & 1 \\
\hline
\end{tabular}

\subsection{Calculation of Posterior Probability of Child Node}

Associated with the prior probabilities of parent nodes and conditional probabilities of intermediate nodes, the posterior probabilities of child nodes can be calculated. The probability of the states of each node can be calculated marginalizing over the states of the node's parents. When evidence is given on any node of a BN, the posterior probability can be calculated using Bayes' theorem [15].

$$
P(A \mid B)=\frac{P(B \mid A) P(A)}{P(B)}
$$

Eq.(5) can be also written in terms of the marginal probability as: 


$$
P(A \mid B)=\frac{\sum_{C} P(A, B, C)}{\sum_{A} \sum_{C} P(A, B, C)}
$$

For the Bayesian network in Fig. 4, the prior probabilities of node A and B is given by two experts, and the conditional probabilities is shown in Table 6. The posterior probability of node $\mathrm{C}$ can be calculated through GeNIe software shown in Fig.9. Under the influence of node $\mathrm{A}$ and $\mathrm{B}$, the posterior probability of node $\mathrm{C}$ is $\{0.75,0.13,0.12\}$.

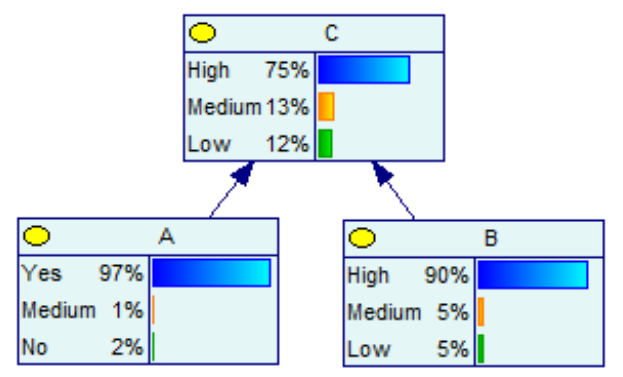

Figure 9. Posterior Probability Inference of Node C

\section{Case Study}

In the high-speed railway, the train driver plays an important role in the safe operation. Once the driver's reliability cannot be guaranteed, it will lead to irreparable accidents. The driver error can be evaluated through the approach above.

The influencing factors includes: self-study, communication, training or experience, stress, abstraction, fit for duty, knowledge. By determining the causal relationships between driver error and influencing factors, its influence diagram can be establish shown in Figure 10.

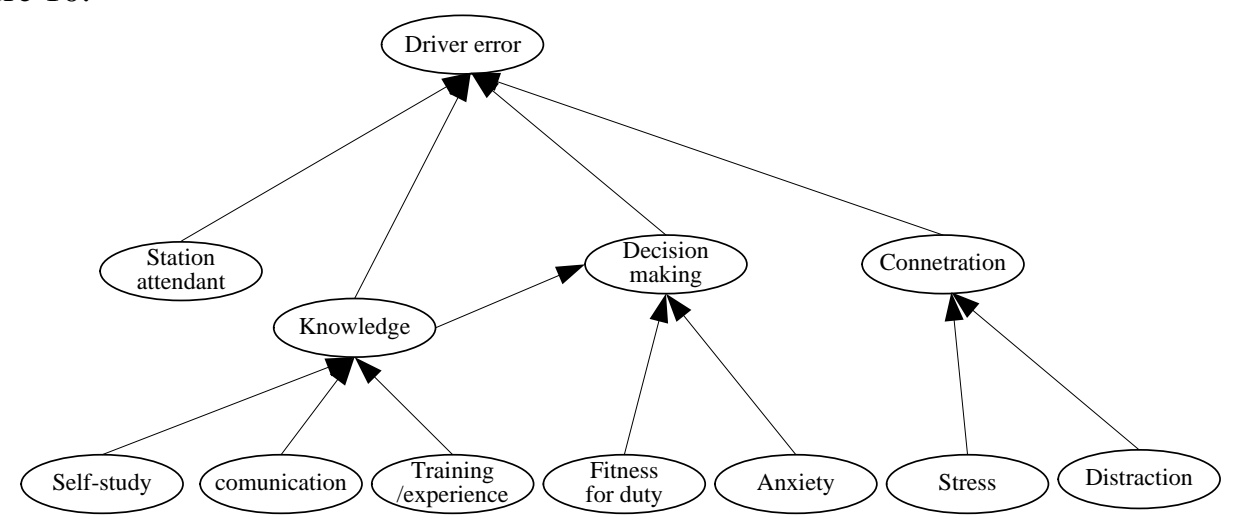

Figure 10. Influence Diagram of Driver Error

This influence diagram can be converted to Bayesian network to assess the probability of driver error. The prior probability of all parent nodes is suggested by two experts, and the evidence combination for each root node is shown in Table 7.

Table 7. Evidence Combination for Factors Related to Driver

\begin{tabular}{llll}
\hline $\begin{array}{l}\text { Influencing } \\
\text { factors }\end{array}$ & Expert & Expert & $\begin{array}{l}\text { Combined } \\
\text { probability }\end{array}$ \\
\hline \multirow{3}{*}{ Self-study } & $\{$ Yes $\}=75 \%$ & Judgment 2 & $\{$ Yes $\}=70 \%$ \\
& $\{$ No $\}=15 \%$ & $\{$ No $\}=20 \%$ & $\{$ Yes $\}=90 \%$ \\
& $\{$ Incomplete & $\{$ Incomplete & $\{$ Incomplete \\
\hline
\end{tabular}




\begin{tabular}{|c|c|c|c|}
\hline & $\begin{array}{l}\text { knowledge }\}=10 \% \\
\{\text { Much }\}=80 \%\end{array}$ & $\begin{array}{l}\text { knowledge }\}=10 \% \\
\{\text { Much }\}=75 \%\end{array}$ & $\begin{array}{l}\text { knowledge }\}=1 \% \\
\{\text { Much }\}=94 \%\end{array}$ \\
\hline Communication & $\begin{array}{l}\{\text { Little }\}=10 \% \\
\{\text { Incomplete } \\
\text { knowledge }\}=10 \% \\
\{\text { Good }\}=75 \%\end{array}$ & $\begin{array}{l}\{\text { Little }\}=15 \% \\
\{\text { Incomplete } \\
\text { knowledge }\}=10 \% \\
\{\text { Good }\}=80 \%\end{array}$ & $\begin{array}{l}\{\text { Little }\}=5 \% \\
\{\text { Incomplete } \\
\text { knowledge }\}=1 \% \\
\{\text { Good }\}=94 \%\end{array}$ \\
\hline Training & $\{\mathrm{Bad}\}=10 \%$ & $\{\operatorname{Bad}\}=5 \%$ & $\{\mathrm{Bad}\}=3 \%$ \\
\hline /experience & $\begin{array}{l}\{\text { Incomplete } \\
\text { knowledge }\}=15 \%\end{array}$ & $\begin{array}{l}\{\text { Incomplete } \\
\text { knowledge }\}=15 \%\end{array}$ & $\begin{array}{l}\{\text { Incomplete } \\
\text { knowledge }\}=3 \%\end{array}$ \\
\hline Anxiety & $\begin{array}{l}\{\text { Low }\}=65 \% \\
\{\text { High }\}=25 \% \\
\{\text { Incomplete } \\
\text { knowledge }\}=10 \%\end{array}$ & $\begin{array}{l}\{\text { Low }\}=75 \% \\
\{\text { High }\}=5 \% \\
\{\text { Incomplete } \\
\text { knowledge }\}=20 \%\end{array}$ & $\begin{array}{l}\{\text { Low }\}=89 \% \\
\{\text { High }\}=9 \% \\
\{\text { Incomplete } \\
\text { knowledge }\}=2 \%\end{array}$ \\
\hline \multirow[t]{2}{*}{ Fit for duty } & $\begin{array}{l}\{\text { High }\}=70 \% \\
\{\text { Low }\}=15 \% \\
\{\text { Incomplete }\end{array}$ & $\begin{array}{l}\{\text { High }\}=75 \% \\
\{\text { Low }\}=15 \% \\
\{\text { Incomplete }\end{array}$ & $\begin{array}{l}\{\text { High }\}=90 \% \\
\{\text { Low }\}=8 \% \\
\{\text { Incomplete }\end{array}$ \\
\hline & $\begin{array}{l}\text { knowledge }\}=15 \% \\
\{\text { Yes }\}=75 \% \\
\{\text { No }\}=15 \% \\
\{\text { Incomplete }\end{array}$ & $\begin{array}{l}\text { knowledge }\}=10 \% \\
\{\text { Yes }\}=70 \% \\
\{\text { No }\}=20 \% \\
\{\text { Incomplete }\end{array}$ & $\begin{array}{l}\text { knowledge }\}=2 \% \\
\{\text { Yes }\}=90 \% \\
\{\text { No }\}=9 \% \\
\{\text { Incomplete }\end{array}$ \\
\hline Distraction & $\begin{array}{l}\text { knowledge }\}=10 \% \\
\{\text { High }\}=15 \%\end{array}$ & $\begin{array}{l}\text { knowledge }\}=10 \% \\
\{\text { High }\}=10 \%\end{array}$ & $\begin{array}{l}\text { knowledge }\}=1 \% \\
\{\text { High }\}=7 \%\end{array}$ \\
\hline \multirow[t]{2}{*}{ Stress } & $\begin{array}{l}\{\text { Low }\}=70 \% \\
\{\text { Incomplete }\end{array}$ & $\begin{array}{l}\{\text { Low }\}=70 \% \\
\{\text { Incomplete }\end{array}$ & $\begin{array}{l}\{\text { Low }\}=89 \% \\
\{\text { Incomplete }\end{array}$ \\
\hline & $\begin{array}{l}\text { knowledge }\}=15 \% \\
\{\text { Right }\}=90 \%\end{array}$ & $\begin{array}{l}\text { knowledge }\}=20 \% \\
\{\text { Right }\}=95 \%\end{array}$ & $\begin{array}{l}\text { knowledge }\}=4 \% \\
\{\text { Right }\}=98 \%\end{array}$ \\
\hline \multirow{3}{*}{ Station attendant } & $\{$ Wrong $\}=5 \%$ & $\{$ Wrong $\}=2 \%$ & $\{$ Wrong $\}=0.3 \%$ \\
\hline & \{Incomplete & \{ncomplete & \{Incomplete \\
\hline & knowledge $\}=5 \%$ & knowledge $\}=3 \%$ & knowledge $\}=1.7 \%$ \\
\hline
\end{tabular}

The conditional probabilities can be allocated through the allocation algorithm based on fuzzy logic above. The allocation for node "Knowledge" is shown in Tab. 8. Other conditional probabilities can be gained in the same way.

Table 8. Conditional Probability Table for Intermediate Node "Knowledge"

\begin{tabular}{|c|c|c|c|c|c|}
\hline \multirow[b]{2}{*}{ Self-study } & \multirow[b]{2}{*}{$\begin{array}{l}\text { Communicati } \\
\text { on }\end{array}$} & \multirow[b]{2}{*}{$\begin{array}{l}\text { Training } \\
\text { lexperience }\end{array}$} & \multicolumn{3}{|c|}{ Knowledge } \\
\hline & & & Much & Medium & Little \\
\hline \multirow{9}{*}{ Yes } & \multirow{3}{*}{ Much } & Good & 0.8 & 0.1 & 0.1 \\
\hline & & Medium & 0.8 & 0.1 & 0.1 \\
\hline & & Bad & 0.1 & 0.8 & 0.1 \\
\hline & \multirow{3}{*}{ Medium } & Good & 0.2 & 0.6 & 0.2 \\
\hline & & Medium & 0.2 & 0.6 & 0.2 \\
\hline & & Bad & 0.2 & 0.6 & 0.2 \\
\hline & \multirow{3}{*}{ Little } & Good & 0.2 & 0.6 & 0.2 \\
\hline & & Medium & 0.2 & 0.6 & 0.2 \\
\hline & & Bad & 0.3 & 0.3 & 0.4 \\
\hline \multirow{7}{*}{ Medium } & \multirow{3}{*}{ Much } & Good & 0.1 & 0.8 & 0.1 \\
\hline & & Medium & 0.1 & 0.8 & 0.1 \\
\hline & & Bad & 0.1 & 0.8 & 0.1 \\
\hline & \multirow{3}{*}{ Medium } & Good & 0.2 & 0.6 & 0.2 \\
\hline & & Medium & 0.3 & 0.4 & 0.3 \\
\hline & & Bad & 0.3 & 0.4 & 0.3 \\
\hline & Little & Good & 0.2 & 0.6 & 0.2 \\
\hline
\end{tabular}




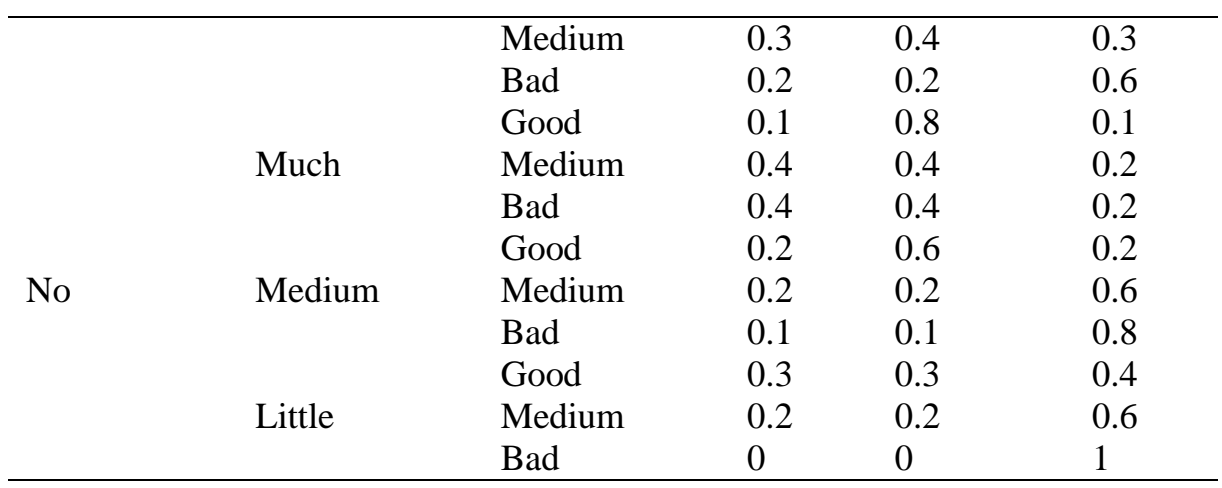

In the Bayesian network of driver error, prior probabilities of parent nodes are gained using evidence theory, and the conditional probabilities are assigned by allocation algorithm based on fuzzy logic. Therefore, the driver error probability can be calculated with GeNIe software, which is not less than 0.14 shown in Figure 11.

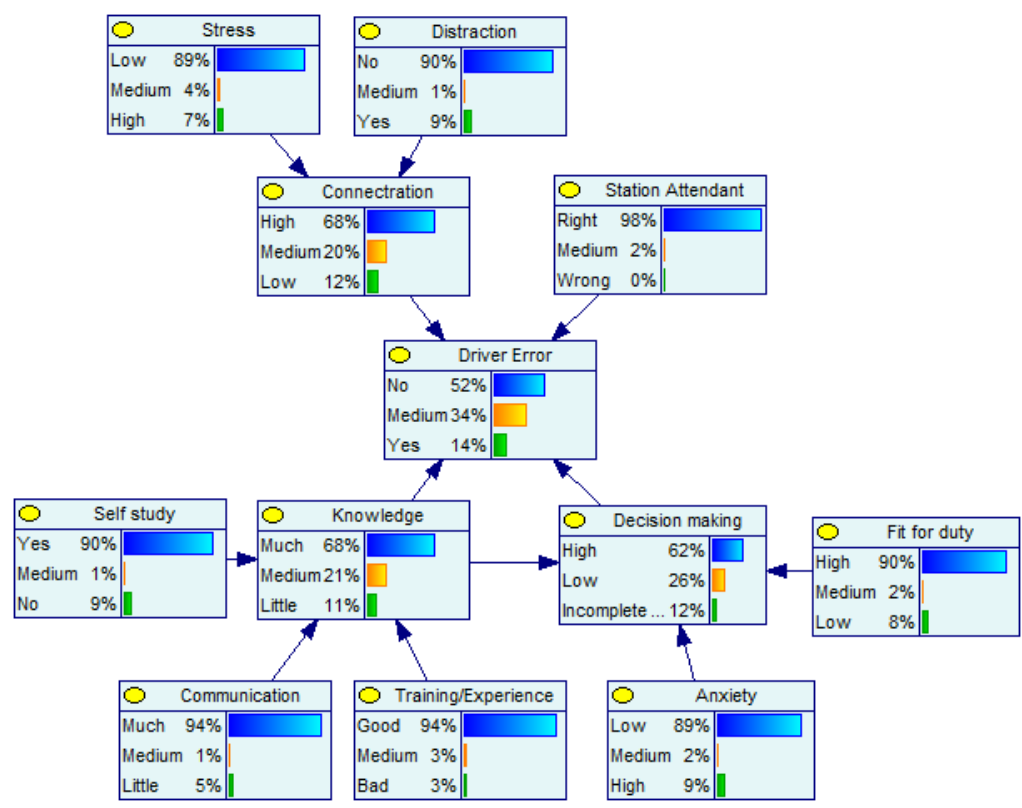

Figure 11. Posterior Probability Inference of Driver Error

\section{Conclusion}

In this paper, the quantitative analysis methodology has been proposed to assess the performance of uncertain factors. This approach includes two stages: modeling and analysis. At the modeling stage, the influence diagram can be established, namely, the structure of Bayesian network can be determined. At the analysis stage, on the basis of the model, quantitative analysis can be achieved to evaluate the probabilities of critical events. In the Bayesian network, the more reliable prior probabilities of parent nodes are obtained using evidence theory. The proposed allocation algorithm of conditional probabilities of intermediate nodes has been complemented to achieve automatic allocation. Combined with the prior and conditional probabilities, the posterior probabilities of child node can be assessed using Bayes' theorem. At last, the feasibility and correctness of this methodology is discussed in the high-speed railway. In addition, the driver error probability is evaluated with GeNIe software using the proposed methodology. 


\section{Acknowledgements}

This work was supported in part by the International Science \& Technology Cooperation Program of China (No. 2012DFG81600).

\section{References}

[1] J. Schutte and M. Geisler, "ROSA-a computer based safety model for European railways [C]", 12th International Conference on Computer System Design and Operation in Railways and Other Transit Systems, (2010).

[2] O. Salvi and B. Debray, "A global view on ARAMIS, a risk assessment methodology for industries in the framework of the SEVESO II directive [J]", Journal of hazardous materials, vol. 130, no. 3, (2006), pp. 187-199.

[3] W. Røed, A. Mosleh and J. E. Vinnem, "On the use of the hybrid causal logic method in offshore risk analysis [J]", Reliability engineering \& System safety, vol. 94, no. 2, (2009), pp. 445-455.

[4] B. J. M. Ale, L. Bellamy and R. Cooke, "Causal model for air transport safety [J]", Final Report, July, (2008), p. 31.

[5] K. Groth, C. Wang and A. Mosleh, "Hybrid causal methodology and software platform for probabilistic risk assessment and safety monitoring of socio-technical systems [J]", Reliability Engineering \& System Safety, vol. 95, no. 12, (2010), pp. 1276-1285.

[6] S. Sklet, T. Aven and S. Hauge, "Incorporating human and organisational factors in risk analysis for offshore installations [J]", Advances in Safety and Reliability, $(\mathbf{1 8 3 9}, 1847)$.

[7] A. Mosleh, E. Goldfeiz and S. Shen, "The $\omega$-factor approach for modeling the influence of organizational factors in probabilistic safety assessment [C]", Human Factors and Power Plants, 1997. Global Perspectives of Human Factors in Power Generation, Proceedings of the 1997 IEEE Sixth Conference on. IEEE, 1997: 9/18-9/23.

[8] S. F. Shen, A. Mosleh and J. M. Izquierdo, "Incorporating organizational factors into probabilistic safety assessment of nuclear power plants through canonical probabilistic models [J]", Reliability Engineering \& System Safety, vol. 92, no. 8, (2007), pp. 1131-1138.

[9] B. Cai, Y. Liu and Z. Liu, "Application of Bayesian networks in quantitative risk assessment of subsea blowout preventer operations [J]", Risk Analysis, vol. 33, no. 7, (2013), pp. 1293-1311.

[10] N. Khakzad, F. Khan and P. Amyotte, "Quantitative risk analysis of offshore drilling operations: A Bayesian approach [J]", Safety science, vol. 57, (2013), pp. 108-117.

[11] D. E. Nordgård and K. Sand, "Application of Bayesian networks for risk analysis of MV air insulated switch operation [J]", Reliability Engineering \& System Safety, vol. 95, no. 12, (2010), pp. 1358-1366.

[12] L. Wang, Y. Wang and Q. Cao, "A framework for human error risk analysis of coal mine emergency evacuation in China [J]", Journal of Loss Prevention in the Process Industries, (2014).

[13] M. Musharraf, J. Hassan and F. Khan, "Human reliability assessment during offshore emergency conditions [J]", Safety science, vol. 59, (2013), pp. 19-27.

[14] K. Sentz and S. Ferson, "Combination of evidence in Dempster-Shafer theory [M]", Albuquerque, New Mexico: Sandia National Laboratories, (2002).

[15] D. Ren, W. Zheng and D. Wu, "Hybrid causal methodology in quantitative risk assessment for the on-board ATP of high speed railway [C]", Intelligent Transportation Systems (ITSC), 2014 IEEE 17th International Conference on. IEEE, (2014), pp. 1577-1582. 
International Journal of Security and Its Applications

Vol.9, No.8 (2015) 